\title{
Assessment of Awareness Among Parents of Children with Thalassemia Major in Bangladesh: A Hospital Based Study
}

\author{
Mohammad Musa Meah ${ }^{1, *}$, Zabeen Choudhury', Mohammad Bani Yeamin², Bimal Chandra Das ${ }^{3}$, \\ Jhulan Das Sharma ${ }^{4}$
}

${ }^{1}$ Department of Pediatrics, Chittagong Medical College Hospital, Chittagong, Bangladesh

${ }^{2}$ Department of Pediatric Hematology \& Oncology, Chittagong Medical College, Chittagong, Bangladesh

${ }^{3}$ Department of Pediatrics, Abdul MalekUkil Medical College, Noakhali, Bangladesh

${ }^{4}$ Southern Medical College Hospital, Chittagong, Bangladesh

\section{Email address:}

meah.musa@gmail.com (M. M. Meah)

${ }^{*}$ Corresponding author

\section{To cite this article:}

Mohammad Musa Meah, Zabeen Choudhury, Mohammad Bani Yeamin, Bimal Chandra Das, Jhulan Das Sharma. Assessment of Awareness Among Parents of Children with Thalassemia Major in Bangladesh: A Hospital Based Study. American Journal of Pediatrics.

Vol. 7, No. 3, 2021, pp. 105-112. doi: 10.11648/j.ajp.20210703.13

Received: April 20, 2021; Accepted: June 3, 2021; Published: June 28, 2021

\begin{abstract}
Introduction: Thalassemia is the world's most common hereditary disease and is a paradigm of monogenic genetic disease. Many children in Bangladesh are carrier of thalassemia which is a major threat for the upcoming generation. The aim of this study was to determine the awareness among parents of children with thalassemia major. Methodology \& Materials: This descriptive cross-sectional study was conducted in the Department of Pediatrics, Chittagong Medical College Hospital, Bangladesh during July 2010 to December 2010. A total of 131 parents of diagnosed cases of thalassemia major children attended for blood transfusion in the Pediatric Ward of Chittagong Medical College Hospital and Thalassemia Centre, Jamal Khan, Chittagong, Bangladesh were enrolled in this study. The collected data were analyzed by the SPSS 23.0 windows version and the association between the categorical variables was assessed through Chi-Squared test where $\mathrm{p}<0.05$ considered as significant. Result: A total of 131 parents of children with thalassemia major were included in this study. The sociodemographic characteristics of the majority parents were low. The educational qualification of the majority father was up to secondary level (29.77\%) and the maximum mother's educational qualification was up to primary level (31.30\%). Most of the parents fully immunized their children according to EPI schedule (73.28\%) but majority of them not received Hepatitis B vaccine $(74.05 \%)$. A large number of parents had no knowledge about consanguinity of marriage $(68.70 \%), 92(70.23 \%)$ parents had no knowledge about mode of inheritance of the disease, 100 (76.34\%) parents had no knowledge about premarital screening, 74.81\% had no other affected children in their family, 42 (32.06\%) parents collected blood from professional blood donors, 47 (35.88\%) parents screened the blood of their children regularly and had knowledge about screening of blood before transfusion for HBV, HCV, HIV, malaria and syphilis were being 19 (14.50\%), $12(9.16 \%), 7(5.34 \%), 6(4.58 \%)$ and 4 $(3.05 \%)$. Parents' knowledge regarding iron overload, iron chelation, oral iron chelation, parenteral iron chelation and use of infusion pump also were being 48 (36.64\%), 42 (32.06\%), 27 (20.61\%), 09 (6.87\%), 06 (4.58\%) and $29(22.14 \%)$. All the above factors were statistically significant $(\mathrm{p}<0.05)$. Conclusion: The awareness and knowledge among parents of children with thalassemia major were insufficient. They have inadequate knowledge regarding the disease, safe blood transfusion and treatments of associated complications. Awareness programs should be taken to improve knowledge among the parents of the children with thalassemia.
\end{abstract}

Keywords: Awareness, Parents, Children and Thalassemia Major 


\section{Introduction}

Thalassemia is a group of autosomal recessive disorder characterized by low production of hemoglobin due to defective synthesis of alpha and beta chain leading to increase destruction of red blood cells [1]. The worldwide prevalence of annually affected conceptions with Beta thalassemia is 42,409 cases with annual births worldwide being 128,667,000 [2]. Thalassemia is the world's most common hereditary disease and is a paradigm of monogenic genetic disease. About $3 \%$ of the world's population carries gene for beta-thalassemia[3]. Thalassemia is a clinically heterogeneous disorder resulting from different genetic lesions that variably impair globin chain synthesis. Furthermore, thalassemia is a serious disease causing severe anemia, ineffective erythropoiesis, extra medullary hematopoiesis, and iron overload resulting from transfusion and increased iron absorption [4, 5]. Bangladesh, having population of over 160 million, there is no national data about the number of thalassemia patients in the country [6]. A recent survey estimated that existing thalassemia patients in Bangladesh is about 1lac and suspected total number of children born with $\beta$-thalassemia major and $\mathrm{Hb}-\mathrm{E} \beta$ thalassemia are around 1040 and 6443per year respectively [7]. Another study conducted in Dhaka, prevailed $67 \%$ of total thalassemia cases were $\mathrm{Hb}$-E $\beta$-thalassemia [8]. A study was conducted in 2013 in Dinajpur Medical College Hospital, Dinajpur, Bangladesh. This study observed that among 60 thalassemia patients, $\mathrm{Hb} \mathrm{E}$ trait was $41.67 \%$ and $\mathrm{Hb} \mathrm{E}$ disease was $30 \%$ and $\mathrm{Hb}-\mathrm{E}-\beta$ thalassemia and $\beta$-thalassemia trait was $23.33 \%, 3.33 \%$ respectively [9]. There is also lack of definitive data regarding existing thalassemia carrier in our country. A conservative WHO report has shown that $3 \%$ of population carries $\beta$-thalassemia and $4 \%$ carries $\mathrm{Hb}$-E in Bangladesh [10]. Thalassemia is a hereditary disease. It is only manageable by taking preventive measures. In the late 1970 s pilot population programs directed to prevent $\beta$ thalassemia major by carrier screening, counseling and prenatal diagnosis started in several at-risk populations in the Mediterranean area like Cyprus, Sardinia and several regions of Continental Italy[11]. At present, several countries like Italy, Greece, Cyprus, UK, France, Iran, Thailand, Australia, Singapore, Taiwan, Hong Kong, Cuba and also in Northern Europe as Netherlands, Belgium and Germany[12] have set up comprehensive national thalassemia prevention programme. In Iran, the annual prevention cost is constant but annual treatment costs rise year by year. National Thalassemia Prevention Program in the Iranian province of Mazandaran demonstrated that an unbearable financial burden can be prevented[13]. Another study conducted in the same country in 2006 at Hajar hospital, reported that significant positive effect of educational programs could increase the knowledge of parents about the disease [14]. But in Bangladesh, there is no national thalassemia prevention programme yet. Thalassemia exists in 3 forms. Thalassemia trait or the asymptomatic carrier stage, that carries a single beta globin mutation is generally asymptomatic except for microcytosis and mild anemia [15]. Thalassemia intermedia have at least 1 beta+thalassemia mutation and less severe phenotype such that they do not require regular transfusion. In thalassemia major or $\beta$-thalassemia major, the production of $\beta$-globin chains is severely impaired, because both $\beta$ globin genes are mutated (homozygous state). The severe imbalance of hemoglobin chain synthesis and production results in ineffective erythropoiesis, severe microcytic, hypochromic anemia leading to early transfusion therapy. Children usually become symptomatic from profound weakness and cardiac decompensation during the latter half of first year. Transfusions begin in the $2^{\text {nd }}$ month to $2^{\text {nd }}$ year of life but rarely later. Affected children fail to thrive and become progressively pale. Bone deformities secondary to marrow expansion, hepato-splenomegaly, cachexia, classical hemolyticfacies (maxilla hyperplasia, flat nasal bridge, frontal bossing) or pathological fractures may develop. Management of patients includes regular blood transfusions to keep $\mathrm{Hb}$ above $9-10 \mathrm{gm} / \mathrm{dl}$, iron chelation therapy to reduce iron overload, surgical interventions like splenectomy. Allogenic hematopoietic transplantation is the definitive curative treatment available till date [16]. To prevent thalassemia, awareness of parents is a must. Improvement of quality of patient care, reinforcement of medical education and enhanced efforts by clinical staff to provide practical knowledge to patients with thalassemia major should significantly improve patient's adherence to treatment [17]. There are a lot of studies where the matter of awareness of parents about thalassemia had been described as one of the most important matter to prevent this disease. The only way to prevent the disease and to reduce the morbidity and mortality is by educating the general population and the best way is to improve the knowledge and awareness of parents of thalassemic children about the disease. So, the researcher purposively designed this study. The aim of this study was to determine the awareness among the parents of children with thalassemia major.

\section{Objectives}

a) General objectives:

To determine the awareness among parents of children with thalassemia major.

b) Specific Objectives:

(1) To determine the knowledge of the parents about the disease.

(2) To determine the awareness of the parents regarding safe blood transfusion.

(3) To assess the knowledge of the parents regarding available treatment facilities

(4) To recommend measures for reducing long term complications and death from thalassemia major.

\section{Methodology \& Materials}

This is a hospital based descriptive cross-sectional study conducted in the Department of Pediatrics, Chittagong 
Medical College Hospital, Chittagong and Thalassemia Centre, Jamal Khan, Chittagong, Bangladesh during July 2010 to December 2010. Sample size of this study was determined on the basis of the following formula: $n=z^{2} \mathrm{pq} / \mathrm{e}^{2}$. Here, $\mathrm{n}=$ Sample size $\mathrm{P}=$ Estimate of prevalence (population proportion) $=50 \%=0$ tab (as exact prevalence for $0-12$ years not found) $\mathrm{q}=1-\mathrm{P}=1-50 \%=50 \%=0.5 \mathrm{e}=$ Acceptance error $=10 \%$ of $\mathrm{P}=0.05 \mathrm{z}=$ The value corresponding to a given confidence level, usually at 1.96 it corresponds to $95 \%$ confidence limit. Thus, $\mathrm{n}=(1.96)^{2} \times 0.5 \times 0.5 /(0.05)^{2}=384$. According to this formula, sample size was calculated as 384 . However, due to time limitation, the convenient cases, a total of 131 diagnosed cases of thalassemia major children, attended in pediatric ward of Chittagong Medical College Hospital and in The Thalassemia Centre, Jamal Khan, Chittagong, Bangladesh for blood transfusion, whose parents were finalized as the study population and were enrolled in this study during the study period. For this study, written approval was taken from the Director of Chittagong Medical College Hospital and Head of the Department of Pediatrics, $\mathrm{CMCH}$ as well as the Director of The Thalassemia Centre, Jamal Khan, Chittagong. The aim and objectives of this study along with its procedures and benefits were explained to the parents of the patients in detail in easily \& perfectly understandable local language. Informed written consent was taken from the parents. The parents were interviewed using a predesigned questionnaire by a single interviewer (Researcher himself- a specialized doctor). Questions regarding the duration of illness, consanguinity of parents, extended family history of thalassemia, source of blood, screening of blood, knowledge about the infections transmitted through blood products, way of prevention from these infections, mode of transmission of disease, their practices regarding iron chelation therapy and antenatal diagnosis were asked. The collected data were analyzed by the SPSS 20.0 Windows version and the association between the categorical variables was assessed through Chi-Squared test where $\mathrm{p}<0.05$ considered as significant.

The inclusion and exclusion criteria of the participants of this study were as follows:

a) Inclusion criteria:

Parents of diagnosed cases of thalassemia major

b) Exclusion criteria:

The parents of the patients admitted for blood transfusion due to other causes like deficiency anemia, aplastic anemia, leukemia etc.

\section{Results}

In this study a total of 131 diagnosed cases of thalassemia children and their parents were enrolled. Table 1 shows the baseline characteristics of the studied children. The educational qualification of father of the majority children was secondary level, 39 (29.77\%), and primary, higher secondary, illiterate, graduate and post graduate were being $27(20.61 \%), 26(19.85 \%), 22(16.79 \%), 15(11.45 \%), 2$ $(1.53 \%), \quad(p=0.950)$. The occupation of father of the maximum children was business, $41(31.30 \%)$, and private job, day laborer, govt. job and others were being $31(23.66 \%)$, $23(17.56 \%)$, and $8(6.11 \%), 28(21.37 \%)(p=0.994)$. The mother's educational qualification of the maximum children was primary, $41(31.30 \%)$, and secondary, illiterate, higher secondary, graduate, post graduate were being $34(25.49 \%)$, $28(31.37 \%), 19(14.50 \%), 7(5.34 \%)$ and $2(1.53 \%)$ $(\mathrm{p}=0.996)$. Mother's occupation of the majority children were housewife, $78(59.54 \%)$ and business, private job, govt. job and others were being 27 (20.61\%), 13 (9.92\%), 9 (6.87\%), 4 $(3.05 \%)$ and $27(20.61 \%),(p=0.981)$. The majority children 96 (73.28\%), were fully immunized. Partial and unimmunized were being $29(22.14 \%)$ and 06 (4.58\%), $(p=0.039)$. Most of the children did not receive Hepatitis B vaccine, $97(74.05 \%)$ and $14(10.69 \%)$ children received 1 doses, $11(8.40 \%)$ children received 2 doses and 9 (6.87\%) children received 3 doses $(p=0.014)$. (Table 2) shows the knowledge of the parents or caregivers of the children regarding the disease. Parents of the studied children having knowledge about consanguinity of marriage was 41 (31.30\%) and $90(68.70 \%)$ parents did not have any knowledge about consanguinity of marriage $(p=0.046)$. The parents having knowledge about mode of inheritance of the disease were 39 $(29.77 \%)$ and $92(70.23 \%)$ parents did not have any knowledge about mode of inheritance of the disease $(p=0.017)$. Parents of the children had knowledge about premarital screening were $31(23.66 \%)$ and $100(76.34 \%)$ parents did not have any knowledge about premarital screening $(\mathrm{p}=0.0134)$. In case of other affected children in the family, the majority parents responded (None) which was $98(74.81 \%)$ and followed by $22(16.79 \%)$ parents (Not known) $8(6.11 \%)$ parents 1 (one) and $3(2.29 \%)$ parents (more than one) $(\mathrm{p}=0.013)$. Regarding the age of the children, at diagnosis of the disease, the maximum patients responded (6-12) months which was 59 (45.04\%) and followed by 37 (28.24\%) patients (<6 months) and $35(26.72 \%)$ parents responded (13-18 months) $(\mathrm{p}=0.443)$. To the query of the total duration of illness of the children from diagnosis, the majority patients responded less than $<1$ years, which was 89 (67.94\%) followed by 21 (16.03\%) (1-3) years, 14 (10.69\%) $(3-4)$ years and $7(5.34 \%)>5$ years $(p=0.7896)$. Regarding the query of unit of blood transfused before HBV vaccine, 14 (10.68\%) parents responded 1 bags, and followed by 7 $(5.34 \%) 2$ bags and $13(9.92 \%)>2$ bags $(p=0.001)$. In the case of average interval between two consecutive transfusions, the maximum parents responded 02 months which was $92(70.22 \%)$ and followed by $29(22.13 \%),<1$ months and $10(7.63 \%),>3$ months (0.014). Table 3 shows the awareness of the parents/ caregivers of the children regarding the safe blood transfusion to thalassemic children. The majority of the parents, $92 \quad(70.22 \%)$ went to Thalassemia Centre, and followed by 39 (29.77\%) to Chittagong Medical College \& Hospital for blood transfusions. The majority of the parents, 42 (32.06\%) sourced blood from professional blood donors and followed by $40(30.53 \%)$ from relatives, $32(24.43 \%)$ from family members and $17(12.98 \%)$ from Sandhani (0.013). The 
majority of the parents of the children $(51.91 \%)$ screened the blood of their children regularly and $45.04 \%$ screened blood irregularly and $3.05 \%$ parents never screened blood or unaware about blood screening $(p=0.014)$. Among the parents of the children, $47(35.88 \%)$ had knowledge about requirement of blood screening before transfusion and 84 $(64.12 \%)$ did not have any knowledge regarding this issue $(p=0.003)$. In analyzing the knowledge of the parents, regarding blood transfusion transmitted infections, we found, $19(14.50 \%)$ parents had knowledge about transfusion transmitted infection of HBV, 12 (9.16\%) had knowledge about transfusion transmitted infection of HCV, 7 (5.34\%) parents had knowledge about transfusion transmitted infection of HIV, $6(4.58 \%)$ parents had knowledge about transfusion transmitted infection of malaria, 4 (3.05\%) parents had knowledge about transfusion transmitted infection of syphilis, 4 (3.05\%) parents had knowledge about transfusion transmitted infection of others and 79 (60.31\%) parents did not have any knowledge about transfusion transmitted infection which was the majority of the parents, $(p=0.001)$. Table 4 shows the knowledge of the parents/caregivers regarding available treatment facilities for the thalassemic children. Regarding this issue, we found 48 (36.64\%) parents had knowledge regarding iron overload and $83(63.35 \%)$ did not have knowledge regarding iron overload $(p=0.035), 42(32.06 \%)$ parents had knowledge regarding iron chelation and $89(67.93 \%)$ parents did not have knowledge regarding iron chelation $(\mathrm{p}=0.021) .27(20.61 \%)$ parents had no knowledge about practices of oral iron chelation therapy, $09(6.87 \%)$ parents had knowledge about practices of parenteral iron chelation therapy and 06 (4.58\%) parents had knowledge about practices of infusion pump iron chelation therapy $(\mathrm{p}=0.003) .29(22.14 \%)$ parents had knowledge regarding infusion pump and 102 (77.86\%) parents did not have knowledge regarding infusion pump $(\mathrm{P}=0.001)$.

Table 1. Baseline characteristics of the studied patients $(n=131)$.

\begin{tabular}{|c|c|c|c|}
\hline Variables & $\mathbf{N}$ & N (\%) & Chi-Squire \& P-Value \\
\hline \multicolumn{4}{|c|}{ Father's qualification: } \\
\hline Illiterate & 22 & 16.79 & \multirow{6}{*}{$(X)^{2}=1.145, d f=5, p=0.950$} \\
\hline Primary & 27 & 20.61 & \\
\hline Secondary & 39 & 29.77 & \\
\hline Higher Secondary & 26 & 19.85 & \\
\hline Graduate & 15 & 11.45 & \\
\hline Post Graduate & 2 & 1.53 & \\
\hline \multicolumn{4}{|l|}{ Father's occupation: } \\
\hline Day labourer & 23 & 17.56 & \multirow{5}{*}{$(X)^{2}=0.213, d f=4, p=0.994$} \\
\hline Govt. Job & 8 & 6.11 & \\
\hline Private Job & 31 & 23.66 & \\
\hline Business & 41 & 31.3 & \\
\hline Others & 28 & 21.37 & \\
\hline \multicolumn{4}{|c|}{ Mother's qualification: } \\
\hline Illiterate & 28 & 31.37 & \multirow{6}{*}{$(X)^{2}=0.370, d f=5, p=0.996$} \\
\hline Primary & 41 & 31.3 & \\
\hline Secondary & 34 & 25.95 & \\
\hline Higher Secondary & 19 & 14.5 & \\
\hline Graduate & 7 & 5.34 & \\
\hline Post Graduate & 2 & 1.53 & \\
\hline \multicolumn{4}{|c|}{ Mother's occupation: } \\
\hline Housewife & 78 & 59.54 & \multirow{5}{*}{$(\mathrm{X})^{2}=0.409, \mathrm{df}=4, \mathrm{p}=0.981$} \\
\hline Govt. Job & 4 & 3.05 & \\
\hline Private Job & 9 & 6.87 & \\
\hline Business & 13 & 9.92 & \\
\hline Others & 27 & 20.61 & \\
\hline \multicolumn{4}{|c|}{ Immunization History:(EPI) } \\
\hline Fully Immunized & 96 & 73.28 & \multirow{3}{*}{$(X)^{2}=6.483, d f=2, p=0.039$} \\
\hline Partial & 29 & 22.13 & \\
\hline unimmunized & 06 & 4.58 & \\
\hline \multicolumn{4}{|c|}{ Hepatitis B Vaccination Status: } \\
\hline 1 dose & 14 & 10.69 & \multirow{4}{*}{$(X)^{2}=10.477, d f=3, p=0.014$} \\
\hline 2 doses & 11 & 8.4 & \\
\hline 3 doses & 9 & 6.87 & \\
\hline None & 97 & 74.05 & \\
\hline
\end{tabular}


Table 2. Theknowledge of the parents/caregivers regarding the disease $(n=131)$.

\begin{tabular}{|c|c|c|c|}
\hline Variables & $\mathbf{N}$ & $\mathbf{N}(\%)$ & Chi-Squire \& P-Value \\
\hline \multicolumn{4}{|c|}{ Consanguinity of marriage: } \\
\hline Yes & 41 & 31.30 & \multirow{2}{*}{$(X)^{2}=3.971, d f=1, p=0.046$} \\
\hline No & 90 & 68.70 & \\
\hline \multicolumn{4}{|c|}{ Mode of inheritance of the disease: } \\
\hline Known & 39 & 29.77 & \multirow{2}{*}{$(X)^{2}=5.655, d f=1, p=0.017$} \\
\hline Not known & 92 & 70.23 & \\
\hline \multicolumn{4}{|c|}{ Knowledge about premarital screening: } \\
\hline Yes & 31 & 23.66 & \multirow{2}{*}{$(X)^{2}=6.106, d f=1, p=0.0134$} \\
\hline No & 100 & 76.34 & \\
\hline \multicolumn{4}{|c|}{ Other affected children in the family: } \\
\hline 01 & 8 & 6.11 & \multirow{4}{*}{$(X)^{2}=2.671, d f=1, p=0.013$} \\
\hline$>1$ & 3 & 2.29 & \\
\hline None & 98 & 74.81 & \\
\hline Not known & 22 & 16.79 & \\
\hline \multicolumn{4}{|c|}{ Age at diagnosis of the disease (months): } \\
\hline$<6$ & 37 & 28.24 & \multirow{3}{*}{$(X)^{2}=1.627, d f=2, P=0.443$} \\
\hline $6-12$ & 59 & 45.04 & \\
\hline $13-18$ & 35 & 26.72 & \\
\hline \multicolumn{4}{|c|}{ Total duration of illness from diagnosis (Years): } \\
\hline$<1$ & 89 & 67.94 & \multirow{4}{*}{$(X)^{2}=1.050, d f=3, P=0.789$} \\
\hline $1-3$ & 21 & 16.03 & \\
\hline $3-4$ & 14 & 10.69 & \\
\hline$>5$ & 7 & 5.34 & \\
\hline \multicolumn{4}{|c|}{ Unit of blood transfused before $\mathrm{HBV}$ vaccine: } \\
\hline 1 bag & 14 & 10.68 & \multirow{3}{*}{$(X)^{2}=22.950, d f=2, P=0.001$} \\
\hline 2 bags & 7 & 5.34 & \\
\hline$>2$ bags & 13 & 9.92 & \\
\hline \multicolumn{4}{|c|}{ Average interval between two consecutive transfusions: } \\
\hline$<1$ month & 29 & 22.13 & \multirow{3}{*}{$(\mathrm{X})^{2}=8.406, \mathrm{df}=2, \mathrm{P}=0.014$} \\
\hline $1-2$ months & 92 & 70.22 & \\
\hline$>3$ months & 10 & 7.63 & \\
\hline
\end{tabular}

Table 3. The awareness of the parents/caregivers regarding safe blood transfusion ( $n=131)$.

\begin{tabular}{llll}
\hline Variables & N & N $(\%)$ & Chi-Squire \& P-Value \\
\hline Preferred centre for regular BT: & 39 & 29.77 & $(\mathrm{X})^{2}=42.705, \mathrm{df}=1, \mathrm{P}=0.001$ \\
Chittagong Medical College \& Hospital & 92 & 70.22 & \\
Thalassemia Centre & & & \\
Source of blood: & 32 & 24.43 & \\
Family members & 40 & 30.53 & $(\mathrm{X})^{2}=10.773, \mathrm{df}=3, \mathrm{P}=0.013$ \\
Relatives & 17 & 12.98 & \\
Sandhani & 42 & 32.06 & \\
Professional donors & & & \\
Screening of blood: & 68 & 51.91 & $(\mathrm{X})^{2}=8.407, \mathrm{df}=2, \mathrm{P}=0.014$ \\
Regularly & 59 & 45.04 & \\
Irregularly & 4 & 3.05 & $(\mathrm{X})^{2}=8.456, \mathrm{df}=1, \mathrm{P}=0.003$ \\
Never & & & \\
Knowledge about requirement of blood screening before transfusion: & 47 & 35.88 & \\
Yes & 44 & 64.12 & \\
No & & & \\
Knowledge regarding transfusion transmitted infections: & 19 & 14.50 & $(\mathrm{X})^{2}=21.228, \mathrm{df}=6, \mathrm{P}=0.001$ \\
HBV & 12 & 9.16 & \\
HCV & 7 & 5.34 & \\
HIV & 6.58 & \\
Malaria & 6 & 3.05 & \\
Syphilis & 4 & 60.31 & \\
Others & 4 & \\
None & 79 & & \\
\hline
\end{tabular}


Table 4. The knowledge regarding available treatment facilities $(n=131)$.

\begin{tabular}{llll}
\hline Variables & N & \% & Chi-Square \& P-Value \\
\hline Knowledge regarding iron overload: & 48 & & \\
Yes & 83 & 36.64 & $(\mathrm{X})^{2}=4.428, \mathrm{df}=1, \mathrm{P}=0.035$ \\
No & 42 & 63.35 & \\
Knowledge regarding iron chelation: & 89 & 32.06 & $(\mathrm{X})^{2}=5.296, \mathrm{df}=1, \mathrm{P}=0.021$ \\
Yes & & 67.93 & \\
No & 27 & 20.61 & $(\mathrm{X})^{2}=11.079, \mathrm{df}=2, \mathrm{P}=0.003$ \\
Practices of iron chelation therapy: & 09 & 6.87 & \\
Oral & 06 & 4.58 & \\
Parenteral & & & \\
Infusion pump & 29 & 22.14 & $(\mathrm{X})^{2}=9.769, \mathrm{df}=2, \mathrm{P}=0.001$ \\
Knowledge regarding infusion pump: & 102 & 77.86 & \\
Yes & &
\end{tabular}

\section{Discussion}

Thalassemia is a genetically transmitted disease which is characterized by decreased in globin chain synthesis of hemoglobin leading to defective erythropoiesis and anemia[18]. The mainstay of treatment option is regular blood transfusion, which may ultimately lead to complications like iron overload and various transfusion related infections like hepatitis B, C, HIV and others. In this study we tried to find out the awareness among the parents of thalassemia major children. In this present study among 131 parents, most of the father's educational qualification was found secondary level, which was 39 (29.77\%), and primary, higher secondary, illiterate, graduate, post graduate were being 27 (20.61\%), 26 (19.85\%), 22 (16.79\%), 15 (11.45\%) and $2(1.53 \%), \quad(p>0.05)$ and the majority mother's educational qualifications were in primary level, which was $41(31.30 \%)$, and the ratio of illiterate, secondary, higher secondary, graduate, and the post graduate were being 28 (31.37\%), 34 (25.95\%), 19 (14.50\%), 7 (5.34\%) and 2 $(1.53 \%) \quad(\mathrm{p}>0.05)$, which indicates that, prevalence of thalassemia is not related to parents' educational qualification. Almost the similar data was found in the study of Goyal JP et al. In their study, they observed, among the 110 fathers of thalassemic children, illiterate was 19 (17.27\%), matriculate (SSC) was $68(61.18 \%)$, below matriculation $23(20.90 \%)$ and among 110 mothers of thalassemic children, illiterate was $21(19.09 \%)$, matriculate (SSC) was $71(65.54 \%)$, below matriculation 18 (16.36\%) [19]. But a study in Pakistan, 2008 claimed, if the parents of children with thalassemia would have higher level of education, they can better understand the importance of prenatal diagnosis[20]. In our study the majority $(31.30 \%)$ of the father's occupation was found business and private job. Day laborer, govt. job, and others were being $23.66 \%, 17.56 \%, 6.11 \%$, and $17.56 \%$ respectively. In relation to occupation, the maximum mother was found housewife $(59.54 \%$ ), and $9.92 \%, 6.87 \%, 3.05 \%$ \& $20.61 \%$ mother involved in business, private, govt. and other jobs, strongly agreed with Manzoor I, et al. (2019) with these findings of our study [21]. In our study, we found, the majority $96(73.28 \%)$ of the children were fully immunized,
$29(22.14 \%)$ parents kept their children partially immunized and 06 (4.58\%) parents kept their children unimmunized. The similar observation was found in the study of Hamid et al, (2008), where $15(12.5 \%)$ parents kept their children unimmunized and $105(87.5 \%)$ parents kept their children fully immunized [22]. Hepatitis B vaccine should be given to all patients with thalassemia before transfusion to prevent transfusion-transmitted hepatitis B [23]. But we found in our study, the majority of the parents $(74.05 \%)$ had taken no initiative for their children to give Hepatitis-B vaccine and 14 $(10.69 \%), 11(8.40 \%)$ and $9(6.87 \%)$ parents were being made their children receiving 1 dose, 2 doses and 3 doses of Hepatitis-B vaccine which was statistically significant $(p<0.05)$, that means there is the difference among the doses received by the children which is the most riskiest factor for prevailing transfusion-transmitted hepatitis- $\mathrm{B}$ in the thalassemic children. In our study, we found 90 (68.70\%) parents did not have any knowledge regarding the consanguinity of marriage which plays a significant role in the transmission of disease whereas only $41(31.30 \%)$ parents were concerned that consanguinity increases the chances of disease in progeny. The percentage of consanguineous marriage observed in our study, was much less than some other studies conducted in Pakistan where cousin marriages were found to be high due to religious and cultural beliefs $[24,25]$. The prevalence of thalassemia increased with consanguineous marriage as it is an autosomal recessive disorder. A study conducted in Iran also found significant association between $\beta$-thalassemia and first cousin marriage[26]. In our study, we observed 39 (29.77\%) parents had knowledge about mode of inheritance of the disease and the majority $92(70.23 \%)$ parents did not have knowledge about mode of inheritance of the disease. Most of the parents, that means, $100(76.34 \%)$ parents did not have any understanding about premarital screening and 31 (23.66\%) parents had knowledge about premarital screening and we also found, the maximum 98 (74.81\%) parents had no other affected members in their family and $8(6.11 \%)$ parents had 1 child and $3(2.29 \%)$ parents had more than one affected children in their family. Similar observation was found in the study of Ali et al. [27]. In our study, we observed, the age at diagnosis of the disease (months) of the children, the 
majority parents 59 (45.04\%) responded (6-12) months, 37 (28.24\%) parents responded, below six months and 35 (26.72\%) parents responded (13-18) months. In our study we found the total duration of illness from diagnosis (years): the majority, $89(67.94 \%)$ parents responded $<1$ year, 21 (16.03\%) parents responded, (1-3) years, 14 (10.69\%) parents responded (3-4) years and 7 (5.34\%) parents responded $>5$ years. We also found, the majority 14 (10.68\%) parents transfused their thalassemic children's blood 1 bag before HBV vaccine followed by 07 (5.34\%), 2 bags and 13 $(9.92 \%)>2$ bags. In average interval between two consecutive transfusions, the maximum parents, $92(70.22 \%)$ responded two months, $29(22.13 \%)$ parents responded $<1$ months, and $10(7.63 \%)$ parents responded $>3$ months and the majority parents, 78 (59.54\%) went to Thalassemia Center for regular blood transfusion of their children and $31(23.66 \%)$ parents went to Chittagong Medical College Hospital and 22 (16.79\%) parents went to Red Crescent Hospital for the same purpose. The maximum parents of the children $42(32.06 \%)$ informed, their blood source for (BT) of their children was professional donors, 40 (30.53\%) from relatives, 32 (24.43\%) from family members and $17(12.98 \%)$ from Sandhani. In our study we found 47 (35.88\%) parents had knowledge about requirement of blood screening before transfusion and $84(64.12 \%)$ parents did not have knowledge about requirement of blood screening before transfusion. Analyzing the knowledge regarding transfusion transmitted infections, we found $19(14.50 \%)$ parents had knowledge about transfusion transmitted infection of HBV, 12 (9.16\%) parents had knowledge about transfusion transmitted infection of HCV, 7 (5.34\%) parents had knowledge about transfusion transmitted infection of HIV, 6 (4.58\%) parents had knowledge about transfusion transmitted infection of malaria, $4(3.05 \%)$ parents had knowledge about transfusion transmitted infection of syphilis, $4(3.05 \%)$ parents had knowledge about transfusion transmitted infection of others and $79(60.31 \%)$ had no knowledge about any transfusiontransmitted infections. Almost the similar observation was found in some other studies [28-30]. In this study $42(32.06 \%)$ parents had knowledge regarding iron chelation. 27 (20.61\%) parents had knowledge about practice of oral iron chelation therapy, 09 (6.87\%) parents had knowledge about practice of parenteral iron chelation therapy and $06(4.58 \%)$ parents had knowledge about practice of infusion pump iron chelation therapy, the similar observation was found in some other studies [31-35].

\section{Limitations of the Study}

As this study was conducted with a small sample size and limited duration, the findings of this study do not reflect the exact scenario of awareness of the parents of the thalassemia major children of the whole country. So, further study is recommended with a large sample size to determine the awareness among parents of children with thalassemia major of the whole country.

\section{Conclusion and Recommendations}

From our study, we can conclude that parental knowledge about the thalassemia major, its ultimate complications and available treatment facilities were inadequate. Most of them don't know about mode of inheritance, importance of premarital screening, which is an important way to prevent the disease transmission. Moreover, they have very poor knowledge regarding transfusion transmitted infections, importance of iron chelation therapy and its various options, which are very essential for long time survival of the patients suffering from thalassemia major. If parents of children with thalassemia would have higher level of knowledge, they can better understand the importance of disease, safe blood transfusions, modern treatment facilities, prenatal diagnosis and other methods of prevention. It is the responsibility of government, health professionals and society to understand the density of problem and educate parents of the children suffering from thalassemia, as well as general public and create awareness among people about modern treatment facilities and to the preventive aspects of thalassemia in order to reduce the burden of the disease in Bangladesh.

\section{References}

[1] Lai K, Huang G, Su L, He Y. The prevalence of thalassemia in mainland China: evidence from epidemiological surveys. Scientific reports. 2017 Apr 19; 7 (1): 1-1.

[2] Sharma S, Seth B, Jawade P, Ingale M, Setia MS. Quality of life in children with thalassemia and their care givers in India. Indian J Pediatr. 2017; 84 (3): 188-194.

[3] Michael R, Baun D, Vichinsky E. Thalassemia syndromes. In: Behrman RE, Kliegman RM, editors. Nelson textbook of paediatircs. $18^{\text {th }}$ ed. New York: WB Saunders; 2007. p. 2033-7.

[4] Borgna-Pignatti C, Gamberini MR. Complications of thalassemia major and their treatment. Expert Rev Hematol 2011; 4: 353-66.

[5] Mishra AK, Tiwari A. Iron overload in beta thalassemia major and intermedia patients. Maedica (Buchar) 2013; 8: 328-32.

[6] Tahura S, Zaman S, Khan Wa. Thalassemia Prevention: Bangladesh Perspective -A Current Update. Bangladesh J Child Health 2016; Vol 40 (1): 31-38.

[7] Khan WA, Banu B, Amin SK. Prevealence of ${ }^{2}$-Thalassemia Trait \& $\mathrm{Hb}$ trait in Bangladesh School Children and Health Burden of Thalassemia in our population. Dhaka Shishu (Children) Hospital Journal. 2005; 21: 1-7.

[8] Rahman SA, Jamal CY. Congenital Haemolytic Anaemia in Bangladesh: Types and Clinical Manifestations. Indian Pediatrics. 2002; 39: 574-77.

[9] Hasan MK, Haque O, Rubaiyat KA, Barshan AD, Talukder SI. Clinical Presentation and Electrophoretic Patterns of Hereditary Haemoglobin Disorders in Adults, a Study at Dinajpur Medical College Hospital. Dinajpur Med Col J. 2013; 6: 167-71. 
[10] Khan WA. Thalassemia in Bangladesh. Dhaka Shishu (Children) Hospital Journal. 1999; 15: 42-44.

[11] Angastiniotis MA, Hadjiminan MG. Prevention of thalassemia in Cyprus. Lancet. 1981; 1: 369-71. 13.

[12] Model B, Darlison M, Birgens H, Cario H, Faustino P, Giordano PC, Gulbis B, Hopmeier P, Lena-Russo D, Romao L. Epidemiology of haemoglobin disorders in Europe: An overview. Scand J Clin Lab Invest. 2007; 67: 39-69.

[13] Karimi M, Johari S, Cohan N. Attitude toward prenatal diagnosis for $\beta$-thalassemia major and medical abortion in Southern Iran. Hemoglobin 2010; 34: 49-54.

[14] Dehkordi AH, Heydernejad MS. Enhancement of parents' awareness about $\beta$-Thalassemia disorder through two educational programs. Pak J Med Sci 2008; 24: 283-6.

[15] Kliegman RM, Stanton B, St. Geme J, Schor NF. Nelson Textbook of Pediatrics. $20^{\text {th }}$ ed. South Asian Edition. 2015; 2: 2352-3.

[16] Bandyopadhyay B, Nandi S, Mitra K, Mandal PK, Mukhopadhyay S, Biswas AB. A comparative study on perceptions and practices among parents of thalassemic children attending two different institutions. Indian J Commun Med. 2003; 28: 128-132.

[17] Ekpemo, S. C. (2018). Challenges and Outcome of Neonatal Surgery at the Abia State University Teaching Hospital Aba Nigeria. American Journal of Biomedical and Life Sciences, 6 (4), 69. doi: 10.11648/j.ajbls.20180604.11.

[18] Galanello R, Origa R. Beta-thalassemia. Orphanet J Rare Dis 2010; 5: 11 .

[19] Goyal JP, Hpapani PT, Gagiya H. Awareness among parents of children with thalassemia major from Western India. Int J Med Sci Public Health 2015; 4: 1356-1359.

[20] Naseem S, Ahmed S, Vahidy F. Impediments to prenatal diagnosis for beta-thalassemia: experiences from Pakistan. Prenat Diagn 2008; 28: 1116-8.

[21] Manzoor I, Zakar R. Sociodemographic determinants associated with parental knowledge of screening services for thalassemia major in Lahore. Pakistan Journal of Medical Sciences. 2019 Mar; 35 (2): 483.

[22] Arif F, Fayyaz J, Hamid A. Awareness among parents of children with thalassemia major. J Pak Med Assoc. 2008 Nov; 58 (11): 621-4.

[23] Di Marco V, Capra M, Angelucci E, Borgna-Pignatti C, Telfer
P, Harmatz P, et al. Management of chronic viral hepatitis in patients with thalassemia: recommendations from an international panel. Blood 2010; 116 (16): 2875-83

[24] Hafeez M, Aslam M, Ali A, Rashid Y, Jafri H. Regional and ethnic distribution of beta thalassemia mutations and effect of consanguinity in patients referred for prenatal diagnosis. $\mathrm{J}$ Coll Physicians Surg Pak 2007; 17: 144-7.

[25] Baig SM, Din H, Azhar A, Baig JM, Aslam M, Anjum I, et al. Prevention of b-thalassemia in a large Pakistani family through cascade testing. Commun Genet 2008; 11: 68-70.

[26] Pooya AA, Doroudchi M. Thalassemia major and consanguinity in Shiraz city, Iran. Turk J Haematol 2004; 21: 127-30.

[27] Ali S, Saffiullah MF. Awareness of parents regarding beta thalassemia major disease. Khyber Med Univ J. 2015 Jun 30; 7 (2): $72-5$.

[28] Hassan K, Aslam M, Ikram N. Parental knowledge and awareness in cases of thalassemia major. J Pak Inst Med Sci 2002; 13: 623-6.

[29] Ishaq F, Abid H, Kokab F, Akhtar A, Mahmood S. Awareness among parents of $\beta$-thalassemia major patients, regarding prenatal diagnosis and premarital screening. J Coll Physicians Surg Pak 2012; 22: 218-21.

[30] Mollah AH, Nahar N, Siddique MD A. Anwar KS, Hassan T, Azam MD G. Common Transfusion-transmitted Infectious Agents among Thalassaemic.

[31] Gardenghi S, Marongiu MF, Ramos P, Guy E, Breda L, Chadburn A, et al. Ineffective erythropoiesis in beta thalassemia is characterized by increased iron absorption mediated by down regulation of hepcidin and up regulation of ferroportin. Blood 2007; 109: 5027-35.

[32] Origa R, Galanello R, Ganz T, Giagu N, Maccioni L, Faa G, et al. Liver iron concentrations and urinary hepcidin in betathalassemia. Haematologica 2007; 92 (5): 583-8.

[33] Giardina PJ, Grady RW. Chelation therapy in beta-thalassemia: an optimistic update. Semin Hematol 2001; 38 (4): 360-6.

[34] Neufeld EJ. Oral chelatorsdeferasirox and deferiprone for transfusional iron overload in thalassemia major: new data, new questions. Blood 2006; 107: 3436-41.

[35] Saxena A, Sharif M, Siddiqui S, Singh S. Knowledge, practice and experiences of parents with a thalassemic child. Int J Contemp Pediatr 2017; 4: 1630-3. 